RASĀYAN J. Chem.

Vol. 13 | No. 1 |339 - 345| January - March | 2020 ISSN: 0974-1496 | e-ISSN: 0976-0083 | CODEN: RJCABP

\title{
DETERMINATION OF THE CONDITIONS OF PHOSPHATE COATINGS FORMATION ON IRON BY VOLTAMMETRIC METHOD
}

\author{
V. N. Statsyuk, A. Bold*, L. A. Fogel, U. Sultanbek and Zh. Tilepbergen \\ D.V. Sokol'skiy Institute of Fuels, Catalysis \& Electrochemistry, Almaty, Kazakhstan \\ *E-mail: b.amangul@inbox.ru
}

\begin{abstract}
This work is devoted to determining the conditions for the deposition of phosphate coatings (time, temperature, accelerator concentration) on a steel base using the method of cyclic voltammetry. It is shown that the optimal conditions for the phosphate coatings formation, determined by the electrochemical method, correlate well with the optimal conditions determined by Akimov's drop method. The influence of the phosphating process accelerator - hydroxylamine on the corrosion resistance and the structure of the formed phosphate coatings is considered.

Keywords: Phosphate Coatings, Cyclic Voltammetry, Akimov's Method, Optimal Conditions, Hydroxylamine.

(C) RASĀYAN. All rights reserved
\end{abstract}

\section{INTRODUCTION}

The processes of deposition anti-corrosion phosphate coatings are widely used in industry, due to their unique functional properties, such as high adhesion strength with a metal base, high adsorption capacity, high antifriction and extrusion properties and low electrical conductivity. ${ }^{1-11}$ However, the determination of optimal conditions of phosphating involves performing a large number of time-consuming tests using chemical and physical methods. ${ }^{12}$ The most common chemical method for determining of the corrosion resistance of formed phosphate coatings is the Akimov's drop method. ${ }^{13}$ This method is based on changing the color of a control solution drop on the test surface. Corrosion tests in the salt fog chamber in accordance with the international standard ASTM B117, adopted in the automotive industry ${ }^{14}$, are also widely used methods for determent corrosion resistance of the coatings obtained. Among the electrochemical methods, the chronopotentiometric method ${ }^{15-17}$ is the most widely used based on measuring the current-free potential in the process of a phosphate coating deposition. However, when considering the dynamics of the phosphating process, this method is not sufficiently informative, since stabilization of the current-free potential lasted for a certain time. In this work, determining the optimal conditions for phosphating iron samples (temperature, phosphating time, influence of hydrodynamic conditions, influence of the phosphating accelerator - hydroxylamine) was carried out using the electrochemical method the cyclic voltammetry method ${ }^{18}$, which allows establishing the relationship of the phosphate coatings corrosion resistance on iron samples with their electrochemical activity.

\section{EXPERIMENTAL}

The reagents sodium sulfate $\mathrm{Na}_{2} \mathrm{SO}_{4}$, zinc oxide $\mathrm{ZnO}$, nickel nitrate $\mathrm{Ni}\left(\mathrm{NO}_{3}\right)_{2} * 6 \mathrm{H}_{2} \mathrm{O}$, nitric acid $\mathrm{HNO}_{3}$, phosphoric acid $\mathrm{H}_{3} \mathrm{PO}_{4}$, sodium hydroxide $\mathrm{NaOH}$, sodium chloride $\mathrm{NaCl}$, copper sulfate $\mathrm{CuSO}_{4} * 5 \mathrm{H}_{2} \mathrm{O}$, hydrochloric acid HCI used in the work had the mark "х.ч" and "ос.ч ". Distilled water was used to prepare the solutions.

Plates of steel (St.3) were used as samples. Pretreatment of metal plates was carried out by degreasing in an aqueous alkaline detergent composition with a concentration of $15-20 \mathrm{~g} / 1$ at a temperature of $60-65^{\circ} \mathrm{C}$ for 2-10 minutes, then the surface of metal plates was cleaned with abrasive material, followed by washing with distilled water.

Rasayan J. Chem., 13(1), 339-345(2020)

http://dx.doi.org/10.31788/RJC.2020.1315460

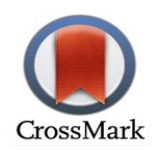


RASĀYAN J. Chem.

Vol. 13 | No. 1 |339 - 345| January - March | 2020

The deposition of phosphate coatings was carried out with stirring on a rotating unit RDE710 with a rotation speed of $500 \mathrm{rpm}$. After coating, the plates were dried at room temperature.

The corrosion resistance of phosphate coatings was determined by the of Akimov's drop method, using a solution containing $\mathrm{CuSO}_{4} * 5 \mathrm{H}_{2} \mathrm{O} ; \mathrm{NaCl} ; \mathrm{HCl}$. According to this method, the protective ability of the coating (ASA) is estimated in seconds as the time of change in the color of the control area under a drop of solution from gray to red-brown.

Electrochemical studies included cyclic voltammetry. Cyclic current-voltage curves were deposited using a Gamry Reference 3000 potentiostat-galvanostat (USA) in a sealed three-electrode cell. The working electrode was an iron electrode St-3 with a visible surface of $0.03 \mathrm{~cm}^{2}$. The counter electrode was a platinum electrode with a surface of $2 \mathrm{~cm}^{2} ; \mathrm{Ag} / \mathrm{AgCI}$ electrode saturated $\mathrm{KCI}$, whose potential is $196 \mathrm{mV}$ relative to the hydrogen electrode, was used as a reference electrode. Before fixing the cyclic current-voltage curves, the working electrode surface was updated with MIRKA 2000 emery paper, washed with distilled water, then polished on a paper filter (blue tape) and finally washed with distilled water. The used electrolyte was a solution of $0.3 \mathrm{M} \mathrm{Na}_{2} \mathrm{SO}_{4}$.

\section{RESULTS AND DISCUSSION}

To establish the relationship of the phosphate coatings corrosion resistance on the iron electrode with their electrochemical activity in the process of cathodic and anodic polarization, the method of cyclic voltammetry was used. Our method of the optimal conditions determined for deposition of phosphate coatings was based on a comparison of cyclic current-voltage curves obtained on an iron disk electrode without a phosphate coating with similar curves deposited on an iron electrode with a phosphate coating. Cyclic current-voltage curves on the iron electrode were obtained in the potential range from $+0.3 \mathrm{~V}$ to $1.2 \mathrm{~V}$ in a solution of $0.3 \mathrm{M} \mathrm{Na}_{2} \mathrm{SO}_{4}$. The phosphating solution FR-1 had the following composition: $\mathrm{ZnO}$ - $1.16 \mathrm{~g} / \mathrm{l} ; \mathrm{NiNO}_{3} .6 \mathrm{H}_{2} \mathrm{O}-0.5208 \mathrm{~g} / \mathrm{l} ; \mathrm{HNO}_{3}-0.614 \mathrm{ml} ; \mathrm{H}_{3} \mathrm{PO}_{4}-1.472 \mathrm{ml} ; \mathrm{NaOH}-0.252 \mathrm{~g} / \mathrm{l}$. In Fig.-1 shows cyclic current-voltage curves obtained on an iron electrode without a phosphate coating (Fig.-1a) and in the presence of a phosphate coating Fig.-1b.
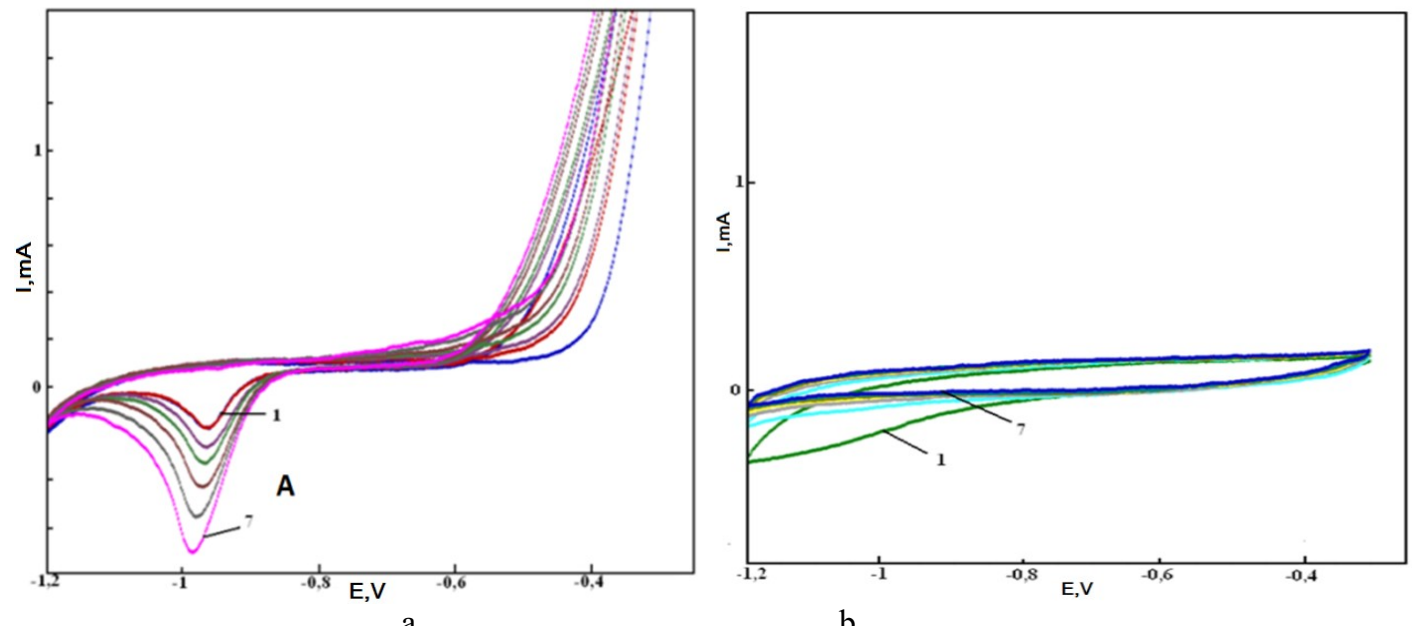

Fig.-1: Cyclic Current-voltage Curves Obtained on An Iron Disk Electrode in $0.3 \mathrm{M} \mathrm{Na}_{2} \mathrm{SO}_{4}$ without a Phosphate Film (a) and in the presence of a Phosphate Film (b)

According to Fig.-1a on cyclic current-voltage curves obtained on the cleaned surface of the iron electrode as the number of cycles increases from 1 to 7 , the magnitude of the maximum (A) cathode current at potential $\mathrm{E}=-0.9 \mathrm{~V}$, caused by the reduction of iron hydroxide compounds formed on the electrode surface in the process of anodic polarization, increases systematically. Whereas the cyclic current-voltage curves of an iron electrode with a phosphate coating Fig. $1 \mathrm{~b}$ have no cathode maximum at $\mathrm{E}=-0.9$ V.Moreover, the opposite effect is observed on the current-voltage curves, due to a decrease in current at potentials close to the potential of the cathode maximum.

A comparison of the curves presented in Fig.-1 $(a, b)$ also makes it possible to note that in the anode region of the cyclic current-voltage curves on the iron electrode with the phosphate film there is practically 
RASĀYAN J. Chem.

Vol. 13 | No. 1 |339 - 345| January - March | 2020

no ionization of the iron electrode. The observed phenomenon may be due to the formation of a protective coating on the electrode surface, causing inhibition of the electrochemical reaction.

Using the method of cyclic voltammetry allows setting the main parameters of the phosphate coating deposition. To establish the optimum parameters of phosphate coating deposition on an iron electrode influence of different factors (time, temperature, stirring speed, the influence of the phosphating process accelerator) on the value of cathode current maximum(A) of the cyclic voltammetric curves was investigated. The maximum current (A) was used to judge the corrosion resistance of the resulting coatings.

The influence of the deposition time of phosphate films on the maximum current (A) was studied. A phosphate coating was deposited on the surface of the iron electrode for various times, after which cyclic current-voltage curves were recorded. Figure-2 shows the dependence of the change in the current maximum (A) in the cathode part of the cyclic current-voltage curves on the time of phosphate coating deposition.

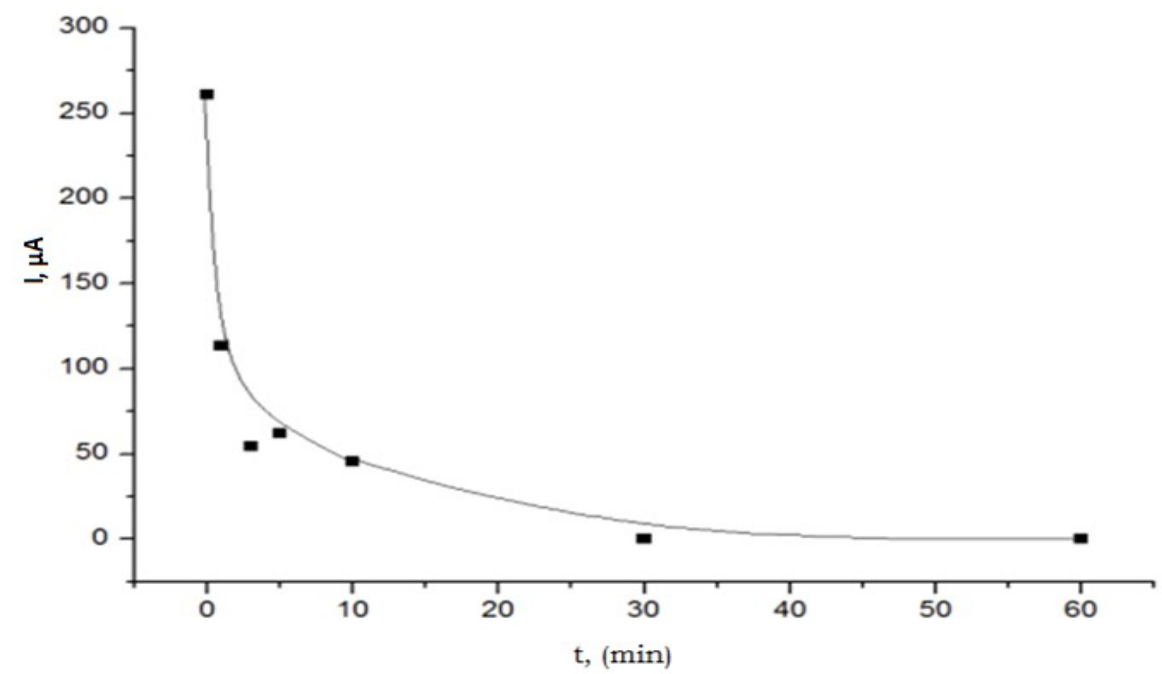

Fig.-2: Effect of the Time Phosphate Coating Deposition on the Current Maximum (A) on the Iron Electrode Cyclic Current-voltage Curves

Phosphate coatings were deposited from the phosphating solution FR-1 at a temperature of $40^{\circ} \mathrm{C}$ and a stirring speed of $500 \mathrm{rpm}$. The effect of deposition time on the properties of phosphate coatings obtained was investigated in the range from 0 to 60 minutes. According to Fig.-2 with an increase in the deposition time of the phosphate coating on the surface of the iron electrode from 0 to $10 \mathrm{~min}$, a sharp decrease in the maximum current (A) is observed, which indicates an increase in the corrosion resistance of the resulting coatings. A further increase in the phosphating time leads to an insignificant decrease in the maximum current (A). Thus, it was found that the optimum formation time of the phosphate coating is 10 minutes.

The influence of deposition temperature on the protective properties of the formed phosphate coating is in the range of 0 to $70^{\circ} \mathrm{C}$ has been studied. Phosphate coatings were deposited from a phosphating solution of FR-1, the deposition time was 10 min., and the stirring speed of the solution was $500 \mathrm{rpm}$. In Fig. - 3 shows the dependence of the maximum current value (A) on cyclic current-voltage curves of an iron electrode with phosphate coatings from a deposition temperature. According to Fig.-3, with an increase, a deposition temperature of a phosphate film from 0 to $30^{\circ} \mathrm{C}$, the current of the cathode maximum (A) on cyclic current-voltage curves decreases sharply. Further temperature increase deposition of the phosphate coating has practically no effect on the maximum current value (A) and respectively on phosphate coating corrosion resistance. It was concluded that the optimum deposition temperature of the phosphate coating deposition is $20-30^{\circ} \mathrm{C}$.

A study of the effect of solution mixing during the formation of a phosphate coating on an iron electrode on the maximum value (A) is shown in Fig.- 4.

The electrolyte is $0.3 \mathrm{M} \mathrm{Na}_{2} \mathrm{SO}_{4}$, phosphating solution FR-1, precipitation time - 10 min, precipitation temperature $40^{\circ} \mathrm{C}$. 
RASĀYAN J. Chem.

Vol. 13 | No. 1 |339 - 345| January - March | 2020

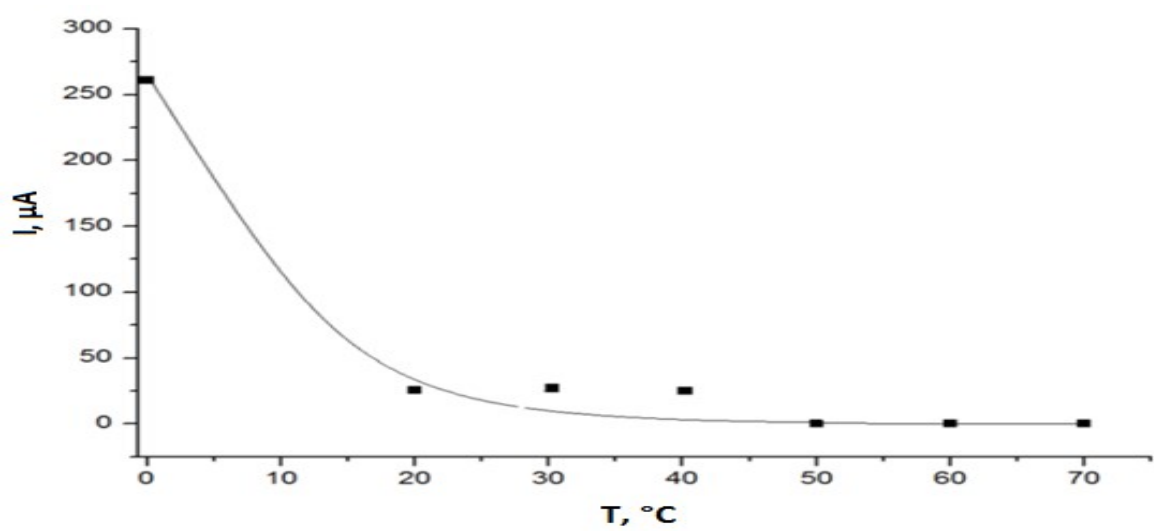

Fig.-3: Effect of Temperature Phosphate Coating Deposition on Current of the Cathode Maximum (A)

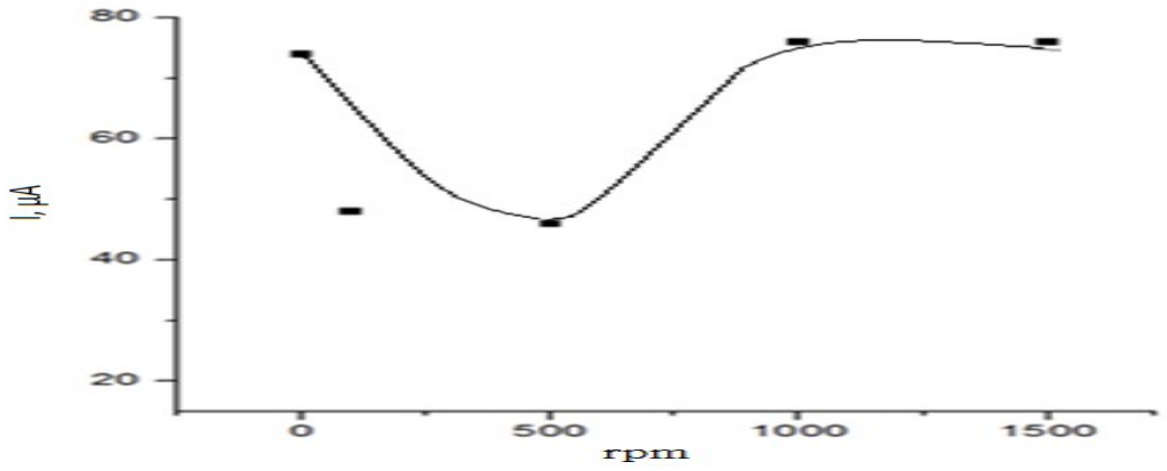

Fig.-4: Effect of Solution Mixing Rate during the Phosphate Film Deposition on the Current Value of the Cathode Maximum (A)

According to Fig.-4 increase, the mixing speed of the solution from 0 to $500 \mathrm{rpm}$ in the process of coating formation leads to a decrease in the maximum current (A) on cyclic current-voltage curves. Further increases in stirring speed lead to the opposite effect - increasing the maximum current (A) and respectively a decrease in corrosion resistance of the formed coating. Thus, the optimal mixing speed at which the coating is formed with the highest corrosion resistance is $500 \mathrm{rpm}$.

The effect of the oxidative accelerator - hydroxylamine added to the phosphate solution, on the corrosion resistance of phosphate coatings on the surface of the iron electrode has been studied. Figure-5 shows the change of the cathodic peak current (A) of the cyclic voltammetric curves of the iron phosphate coating electrode on the concentration of hydroxylamine in the phosphating solution.

The conditions of phosphate coating deposition: phosphating solution FR-1, temperature $-40^{\circ} \mathrm{C}$, deposition time - $10 \mathrm{~min}$, stirring speed $-500 \mathrm{rpm}$. The concentration of hydroxylamine was changed from 0.1 to $2 \mathrm{~g} / 1$. According to Fig.-5 the minimum of the maximum current value (A) on cyclic current-voltage curves is observed at a hydroxylamine concentration in the phosphating solution of 0.3 to $0.5 \mathrm{~g} / \mathrm{l}$. With a further increase in the concentration of hydroxylamine, an increase in the maximum current (A) is observed, which is associated with a decrease in the corrosion resistance of the formed phosphate coating. Consequently, the optimal concentration of hydroxylamine, at which the formed coatings have the maximum protective ability, is a concentration of $0.3-0.5 \mathrm{~g} / 1$.

Importantly, the main parameters of the phosphate coating deposition (temperature, time, speed stirring, the concentration of hydroxylamine) determined by an electrochemical method - a method of the cyclic voltammetry are well correlated with main phosphate coating deposition parameters determined by Asimov's dropping method. Figure-6 shows the effect of hydroxylamine concentration in the phosphating solution on the corrosion resistance of the formed phosphate coatings on iron samples, determined by the Akimov's dropping method. 
RASĀYAN J. Chem.

Vol. 13 | No. 1 |339 - 345| January - March | 2020

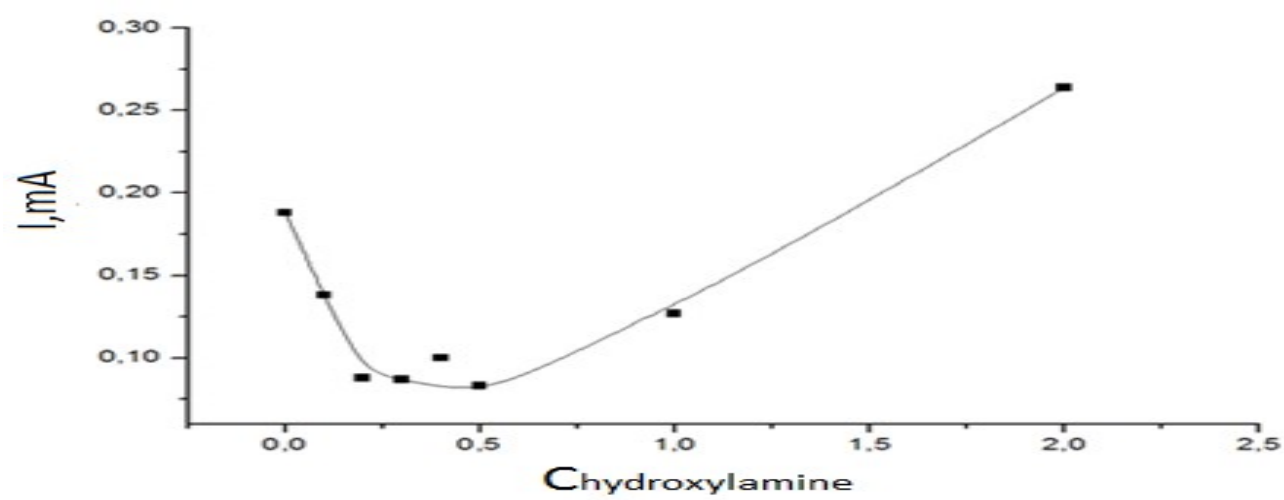

Fig.-5: Effect of Concentration Hydroxylamine on Maximum Current Value (A) on Cyclic Current-voltage Curves (2 cycles) of an Iron Electrode with a Phosphate Coating

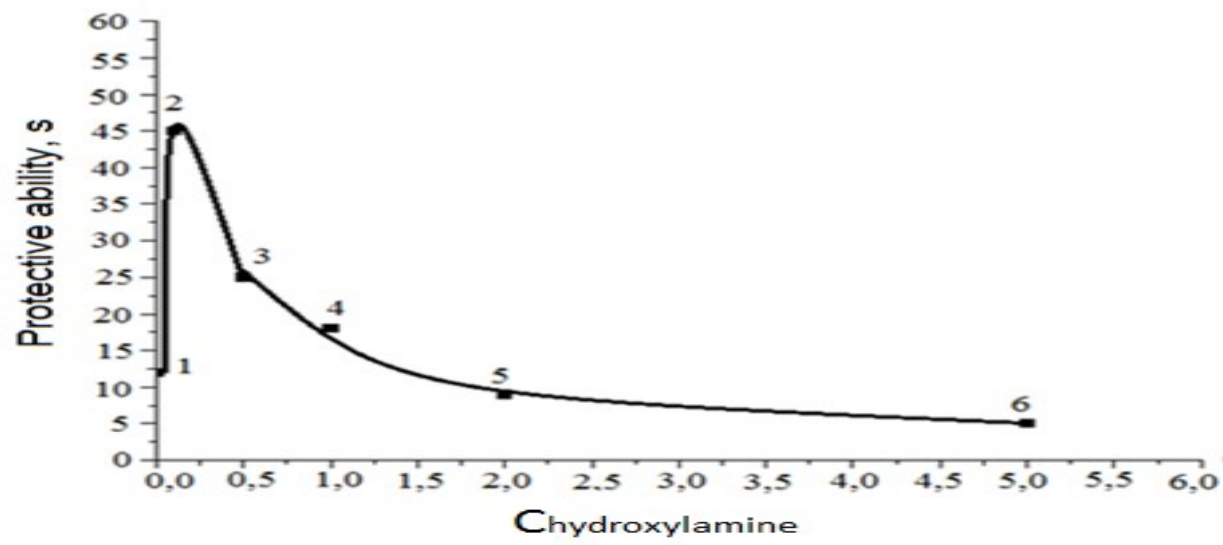

Fig.-6: Effect of Hydroxylamine Concentrations in the Phosphating Solution FR-1 on the Corrosion Resistance of Phosphate Coatings

According to Fig.-6 maximum protective ability of phosphate coating (ASA) received from the phosphating solution FR-1, observed at a concentration of 0.3-0.4 g/ 1 , hydroxylamine which is consistent with the optimal concentration of hydroxylamine, certain electrochemical method (Fig.-5).

The effect of hydroxylamine on the corrosion resistance of the phosphate coating formed on the iron electrode is clearly seen in Fig.-7, in which the dependencies of the change in the maximum current value (A) on the cyclic current-voltage curves on the number of cycles are compared.

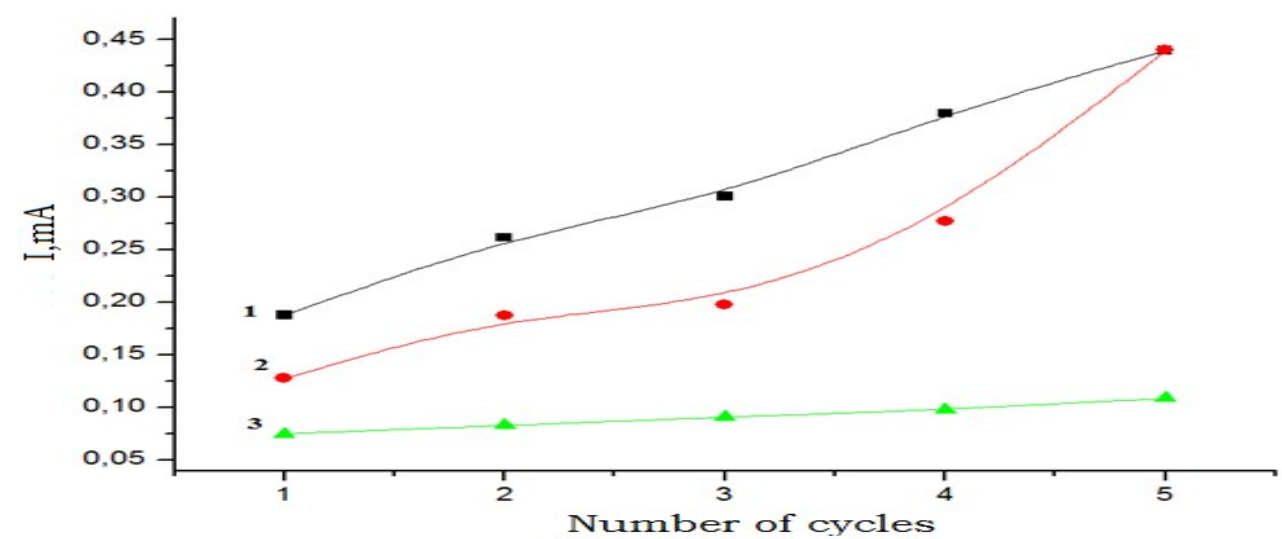

Fig.-7: Effect of the Number of Current-voltage Cycles of the Iron Electrode on the Maximum Current (A)

Curve 1, Fig.-7 corresponds to a change in the maximum current (A) on the cyclic current-voltage curves of the iron electrode without a protective phosphate coating. Curve 2 (Fig.-7) corresponds to a change in 
RASĀYAN J. Chem.

Vol. 13 | No. 1 |339 - 345| January - March | 2020

the maximum current (A) on the cyclic current-voltage curves of an iron electrode with a phosphate coating deposited in the absence of hydroxylamine in the phosphating solution. Curve 3 (Fig.-7) corresponds to the change in the maximum current (A) on the cyclic current-voltage curves of a phosphate-coated iron electrode in the presence of hydroxylamine in the phosphating solution. According to Fig.-7, with an increase in the number of cycles, an increase in the maximum current (A) on curves 1 and 2 is observed, which is due to the destruction of the protective oxide film on the surface of iron (curve 1) and the phosphate coating obtained from the phosphating solution in the absence of hydroxylamine (curve 2). The presence of hydroxylamine in the phosphating solution (curve 3) contributes to the formation of a phosphate coating on the surface of the iron electrode, which has high corrosion resistance and is almost unbreakable with an increasing number of current-voltage curves cycles.

\section{CONCLUSION}

On the basis of the studies made, the optimal conditions (deposition time, temperature, hydrodynamic conditions, accelerator concentration) were determined to deposition phosphate coatings from the FR-1 phosphating solution on steel substrate by the electrochemical method (cyclic voltammetry). The influence of the phosphating process accelerator, hydroxylamine, on the corrosion resistance of the phosphate coatings formed is determined. It is shown that the optimal conditions determined by the electrochemical method correlate well with the optimal conditions for the formation of phosphate coatings determined by Akimov's drop method.

\section{ACKNOWLEDGMENT}

This work was conducted under research grand project of AP05133055 "Development of anti-corrosive phosphate materials for oilfield equipment" and AP05132222 "Development of resource-saving technology for applying ceramic adhesive nanocoatings with improved characteristics". The authors would like to place on record their sincere gratitude to the Ministry of Science and Education of the Republic of Kazakhstan for financial support.

\section{REFERENCES}

1. I.A. Kazarinov, A.A. Makhmmod, N.M. Trepak and L.A. Isaycheva, Eurasian Union of Scientists, 3, 101(2016).

2. N.S. Grigoryan, E.F. Akimova and T.A. Vahramyan, Phosphating, Globus, Moscow, p.144, 91(2008).

3. R. Ramanauskas, O. Girčienè, L. Gudavičiūtè, and A. Selskis, Applied Surface Science, 327, 131(2015), DOI:10.1016/j.apsusc.2014.11.120

4. M. Tamilselvi, P. Kamaray, M. Arthanareeswari and S. Devikala, Applied Surface Science, 327, 218(2015), DOI:10.1016/j.apsusc.2014.11.081

5. I. Liascukiene, M SalahBen, R. Sabot, Ph. Refait, L. Dhouibi, C. Méthivier, J. Landoulsi and M. Jeannin, Applied Surface Science, 434(3), 561(2018), DOI:10.1016/j.apsusc.2017.10.153

6. Y. Xie, M. Chen, D. Xie, L. Zhong and X. Zhang, Corrosion Science, 128(11), 1(2017), DOI:10.1016/j.corsci.2017.08.033

7. M. Zubielewicz, E.Kamińska-Tarnawska and A. Kozłowska, Progress in Organic Coatings, 53, 276285(2005), DOI:10.1016/j.porgcoat.2005.02.008

8. H. Verbruggenn, K. Baert, H. Terryn and I Graeve De, Surface and Coatings Technology, 361(15), 280(2019), DOI:10.1016/j.surfcoat.2018.09.056

9. R. Amini, H. Vakili and B. Ramezanzadeh, Journal of the Taiwan Institute of Chemical Engineers, 58, 542(2016), DOI:10.1016/j.jtice.2015.06.024

10. B.V. Jegdić, J.B. Bajat, J.P. Popić and V.B. Mišković-Stanković, Progress in Organic Coatings, 70(2-3), 127 (2011), DOI: 10.1016/j.porgcoat.2010.11.004

11. Y. Hao, F. Liu, E. Han, S. Anjum and G. Xu, Corrosion Science, 69(4), 77(2013), DOI:10.1016/j.corsci.2012.11.025

12. T.K. Akayeva, O.N. Rodin, V.V. Gunin, and O.P. Akayev, Bulletin of Kostroma State University, 5, 39(2014).

13. State Standard 9,302-88, ESZKS, Metallic and Nonmetallic Coatings, Methods of Accelerated Corrosion Tests. 
RASĀYAN J. Chem.

Vol. 13 | No. 1 |339 - 345| January - March | 2020

14. State Standard 9,401-91, ESZKS, Lacquer Coatings. General Requirements and Methods of Accelerated Tests for Stability to Effect of Climatic Factors, Method B "Determination of Stability of Coatings to the Effect of Salt Mist (Development of Corrosion from a Cut)".

15. A. A. Abrashov, N.S. Grigoryan, T.A. Vagramyan and E.F. Akimova, Electroplating and Surface Treatment, 18(3), 48(2010).

16. A. A. Abrashov, N.N. Chamashkina, G.A. Yur eva, N.S. Grigoryan and T.A. Vagramyan, Electroplating and Surface Treatment, 20(4), 7(2012).

17. A.A. Abrashov, N.S. Grigoryan, T.A. Vagramyan, R.V. Papirov and M.I. Styazhkina, Electroplating and Surface Treatment, 21(4), 40(2013).

18. V. N. Statsyuk, L. A. Fogel, and A. Bold, News of the National Academy of Sciences of Kazakhstan, 2, 129 (2016).

[RJC-5460/2019] 